\title{
Screening Flavonoids for Inhibition of Acetylcholinesterase Identified Baicalein as the Most Potent Inhibitor
}

\author{
Azize Balkis ${ }^{1}$, Khoa Tran ${ }^{1}$, Yan Zhi Lee ${ }^{1} \& \mathrm{Ken} \mathrm{Ng}^{1}$ \\ ${ }^{1}$ Faculty of veterinary \& Agricultural sciences, University of Melbourne, Melbourne, Victoria, Australia \\ Correspondence: Ken Ng, Faculty of Veterinary \& Agricultural Sciences, University of Melbourne, Royal \\ Parade, Melbourne, Victoria 3010, Australia. Tel: 61-3-9035-3141. E-mail: ngkf@unimelb.edu.au
}

Received: June 7, 2015 Accepted: June 30, 2015 Online Published: August 15, 2015

doi:10.5539/jas.v7n9p26 URL: http://dx.doi.org/10.5539/jas.v7n9p26

\begin{abstract}
Screening phenolic and polyphenolic compounds for inhibitory activity against electric eels acetylcholinesterase (AChE) identified baicalein, a major flavone derived from the roots of Scutellaria baicalensis, as the most potent inhibitor with IC50 (concentration required for 50\% inhibition) of $0.61 \mu \mathrm{M}$. None of the hydroxybenzoic and hydroxycinnamic acids screened showed inhibitory activity measured at $100 \mu \mathrm{M}$. Structure-activity relationships based on IC50 values of the active flavonoids showed that inhibitory activity (a) required the unsaturated 2-phenyl-chroman structure, (b) has strong requirement for the A-ring A5-OH, A6-OH and A7-OH groups (b) does not depend on B-ring hydroxyl groups, and (d) was reduced by bulky sugar substitution of the saturated C-ring $\mathrm{C} 3-\mathrm{OH}$. Enzyme kinetic analysis showed that baicalein is a mixed inhibitor of $\mathrm{AChE}$ with $\mathrm{K}_{1}$ (equilibrium constant of dissociation of the inhibitor bound enzyme complex) and $\mathrm{K}_{2}$ (equilibrium constant of dissociation of the inhibitor bound enzyme-substrate complex) of 0.91 and $1.98 \mu \mathrm{M}$, respectively.
\end{abstract}

Keywords: Alzheimer's disease, acetylcholinesterase inhibitors, baicalein, Scutellaria baicalensis, structure-activity relationships

\section{Introduction}

Alzheimer's disease (AD) is a progressive neurodegenerative disorder and is the most prevalent form of dementia in elderly people. The hall marks of $\mathrm{AD}$ are cholinergic system dysfunction, accelerated aggregation of $\beta$-amyloid peptides (A $\beta$ ) and loss of cognitive function (Hardy \& Selkoe, 2002; Holtzman, John, \& Goate, 2011). These factors provide a basis for the cholinergic and amyloid hypotheses for AD pathology, respectively.

According to the cholinergic hypothesis, the cognitive and memory symptoms of $\mathrm{AD}$ are caused by the drastic decline of acetylcholine in the brain (Mesulam, Guillozet, Shaw, Levey, Duysen, \& Lockridge, 2002; Nigel et al., 2005). The amyloid cascade hypothesis attributes the pathogenesis of $A D$ to the accelerated aggregation of $A \beta$ peptide in the brain resulting in the formation of senile plaques that contributes to neuronal cell death and, ultimately, dementia (Racchi, Mazzuccelli, Porrello, Lanni, \& Govoni, 2004; Holtzman et al., 2011). Therefore, preventing $\mathrm{A} \beta$ aggregation is a potential therapy for $\mathrm{AD}$. In addition, elevated $\mathrm{AChE}$ activity in brain has been linked to increased plague deposition (Geula \& Darvesh, 2004).

Studies have shown that inhibition of acetylcholinesterase (AChE) improves both cognitive and memory symptoms in AD. Thus, current therapy for AD focuses on increasing cholinergic neurotransmission by $\mathrm{AChE}$ inhibitors such as donepezil, rivastigmine and galantamine that have shown to improve symptoms for most patients (Marek, Wieckowska, Hebda, Guzior, Sotriffer, \& Malawska, 2013). However, these drugs have side-effects issues which are exacerbated by their long term used as required for AD treatment in addition to the cost of therapy (Wollen, 2010; Anand \& Singh, 2013; Tayeb, Yang, Price, \& Tarazi, 2012).

Recent interest on $\mathrm{AD}$ prevention and management has focused on naturally occurring AChE inhibitors especially from herbs and plants. In particular, polyphenolic compounds such as flavonoids have been studied as AChE and BChE inhibitors (Khan et al., 2009; Guo et al., 2010; Katalinic et al., 2010; Kim et al., 2011; Mehta, Adem, \& Sabbagh, 2012). While polyphenolic compounds with inhibitory potency matching those of the currently prescribed AChE inhibitor drugs has yet to be found, they have the advantages of been more tolerable and cheaper as they are commonly found in and consumed from foods. Additionally, many of these flavonoids are potent antioxidants and strong metal chelator which might contribute to mitigating oxidative stress of 
affected tissues associated with $\mathrm{AD}$ (Li, Wang, Hu, \& Kong, 2013).

Herbs and plants have a long history of used in Traditional Chinese Medicine for alleviating the symptoms of memory loss (Adam, Gmunder, \& Hamburger, 2007). Baicalein, a major bioactive flavonoid found in the roots of Scutellaria baicalensis, has been reported to facilitate memory retention (Wang et al., 2011) and correct cognitive deficits (Liu, Wu, Gu, Xiong, F. Wang, \& J. Wang, 2007) in rats.

In the present study, we screen the inhibitory effect of several hydroxycinnamates, hydroxybenzoates, flavanols, flavanones, flavones, isoflavones, flavonols and anthocyanidins and in addition to curcumin (curcuminoids) and resveratrol (stilbenes) against electric eels AChE activity under the same assay conditions in order to derive some structure-activity relationship. In the process we identified baicalein as the most potent polyphenolic inhibitor. We also determined the inhibitory kinetics of baicalein against electric eel's AChE.

\section{Materials and Methods}

\subsection{Materials}

Acetylcholinesterase from electric eel (C2888), acetylthiocholine iodide (ATCI; A5751), 5'5-dithio-bis-(2-nitrobenzoic) acid (DTNB; D8130) and tacrine (A79922) were from Sigma-Aldrich (Castle Hills, NSW). The following phenolic acids and flavonoids were also purchased from Sigma-Aldrich: Apigenin (A3145), baicalein (465119), baicalin (572667), caffeic acid (C0625), chrysin (C80105), trans-4-hydroxycinnamic acid ( $p$-coumaric acid; C9008) curcumin (08511), cyanidin chloride (79457), daidzein (D7802), delphinidin chloride (43725), 3,4-dihydroxybenzoic acid (protocatechuic acid; 37580), trans-3,4-dihydroxycinnamic acid (caffeic acid; C0625), (-)-epigallocatechin (E3768), (-)-epigallocatechin gallate (E4143), fisetin (F4043), galangin (282200), genistein (G6649), 4-hydroxybenzoic acid (240141), isoquercitrin (quercetin 3-O- $\beta$-D-glucoside; 17793), kaempferol (K0133), malvidin chloride (68120), myricetin (70050), naringenin (N5893), oroxylin A (O0641), pelargonidin chloride (P1659), pinocembrin (P5239), quercetin (Q0125), resveratrol (R5010), rutin (quercetin 3-O- $\beta$-D-rutinoside; R5143) and 3,4,5-trihydroxybenzoic acid (gallic acid; 398225).

Icarin and baohuoside I (synonyms: icarin II, icariside II) were of HPLC purified grade ( $>98 \%$ pure) from $E$. brevicornum leaves and were purchased from Chengdu Biopurify Pty. Ltd. (Chengdu, China).

All other chemicals and organic solvents used were of analytical-grade or better. Deionised water $(\leq 18 \mathrm{M} \Omega)$ used was produced using a Synergy UV Millipore System (Millipore).

\subsection{Assay of Acetylcholine Esterase (AChE) Activity}

AChE activity was assayed by the spectrophotometric Ellman's method (1961). The reaction mixture consisted of $600 \mu \mathrm{L}$ water, $100 \mu \mathrm{L}-1 \mathrm{M}$ potassium phosphate buffer (pH 7.4), $100 \mu \mathrm{L}$ inhibitor (in methanol) and 100 $\mu \mathrm{L}-27 \mathrm{mU} / \mathrm{mL}$ AChE (in $100 \mathrm{mM}$ potassium phosphate buffer). The mixture was preincubated at $37^{\circ} \mathrm{C}$ for $5 \mathrm{~min}$ before starting the reaction by adding $100 \mu \mathrm{L}-2.5 \mathrm{mM}$ of ATCI (in water) and the reaction continued for another $60 \mathrm{~min}$ at $37^{\circ} \mathrm{C}$. The final reaction mixture consisted $1000 \mu \mathrm{L}$ containing: $110 \mathrm{mM}$ potassium phosphate buffer (pH 7.4), $0-100 \mu \mathrm{M}$ inhibitor, $2.7 \mathrm{mU} / \mathrm{mL}$ of AChE, $250 \mu \mathrm{M}$ ATCI and $10 \%$ methanol (v:v). $200 \mu \mathrm{L}-25 \mathrm{mM}$ DTNB (in ethanol) was added to terminate the reaction which also yield the yellow color chromophore, 5-thio-2-nitrobenzoic acid. AChE activity was indirectly determined by absorbance measurement of the formation of 5-thio-2-nitrobenzoic acid at $\lambda_{410 \mathrm{~nm}}$ using a spectrophotometer (Novaspec II, USA). Absorbance of blank samples was also determined to correct for background color contributed by inhibitor and/or DTNP.

AChE inhibition percentage was calculated according to the following equation:

$$
\% \text { Inhibition }=\frac{\left[\left(A b s_{\text {control }}-A b s_{\text {background }-1}\right)-\left(A b s_{\text {inhibitor }}-A b s_{\text {background }-2}\right)\right]}{\left(A b s_{\text {control }}-A b s_{\text {background }-1}\right)} \times 100 \%
$$

$\mathrm{Abs}_{\text {control }}$ : Absorbance for control (100\%) enzyme activity (-Inhibitor +Enzyme +ATCI +DTNB);

$\mathrm{Abs}_{\text {inhibitor }}$ : Absorbance for enzyme activity with inhibitor (+Inhibitor +Enzyme +ACTI +DTNB);

$\mathrm{Abs}_{\text {background-1 }}$ : Background absorbance without inhibitor (-inhibitor +Enzyme -ATCI +DTNB);

$\mathrm{Abs}_{\text {background-2: }}$ : Background absorbance with inhibitor (+inhibitor +Enzyme -ATCI +DTNB).

One unit of $\mathrm{AChE}$ was defined as the enzyme activity that releases $1 \mu \mathrm{mol}$ of thiocholine from acetylthiocholine in $1 \mathrm{~min}$ at $37^{\circ} \mathrm{C}$. AChE activity was compatible with $10 \%$ methanol, retaining $>95 \%$ of enzyme activity.

\subsection{Determination of IC50}

Inhibitory compounds were assessed for their potency by their IC50 values, which is defined as the concentration 
of an inhibitor $(\mu \mathrm{M})$ required for reducing $50 \%$ of the enzyme activity compared to a control reaction without added inhibitor. The IC50 value for each inhibitor was obtained from the plot of Mean-\%-Inhibition verse log $\mu \mathrm{M}$ (inhibitor) and data points fitted by linear regression line $(n \geq 3)$ (Burlingham \& Widlanski, 2003). The standard deviation of value was reported as the uncertainty of the linear regression (Ellison \& Williams, 2012).

\subsection{Determination of the Inhibitory Mode of Action of Baicalein}

The kinetic mode of inhibition of baicalein against eel acetylcholinesterase was determined by preparing a series of sample solutions $(900 \mu \mathrm{L})$ in which the concentration of the ATCI substrate was varied in the absence or presence of different concentrations of the inhibitor $(100 \mu \mathrm{L}$ in methanol). The mode of inhibition (i.e. competitive, non-competitive, uncompetitive or mixed-type) of the test compounds was evaluated on the basis of the inhibitory effects on the enzyme $\mathrm{Km}$ (dissociation constant) and $\mathrm{V}_{\max }$ (maximum reaction velocity) (Burlingham \& Widlanski, 2003). This can be determined using the Lineweaver-Burk plot, which is the double reciprocal plot of enzyme reaction velocity $(\mathrm{V})$ versus substrate (ACTI) concentration (1/V versus 1/[ACTI]). Analysis of the same data by secondary plots of slope versus [Inhibitor] and Y-intercept versus [Inhibitor] were also carried out.

\subsection{Statistical Analysis}

Inhibition percentages and IC50 values were expressed as Mean \pm SD from replicate determinations $(\mathrm{n} \geq 3)$. Uncertainty of the mean was reported to 2 significant figures according to the European Analytical Chemist guidelines (Ellison \& Williams, 2012). Statistical comparisons of means were performed using one-way analysis of variance (ANOVA) and followed by the Fisher's protected Least Significant Difference Test using SAS software version 9.2. Analyses with $\mathrm{p}<0.05$ were considered to be statistically different.

\section{Results and Discussion}

\subsection{Assay of Acetylcholine Esterase (AChE) Activity}

AChE activity from electric eel was measured by the spectrophotometric Ellman's method using acetylthiolcholine iodide (ATCI) as substrate. The activity was detected by the formation of formation of 5-thio-2-nitrobenzoic acid formed from the reaction between 5'5-dithio-bis-(2-nitrobenzoic) acid and thiocholine, the later liberated from ACTI by the enzyme. A number of factors need to be considered in measuring AChE activity and accessing inhibition potency of compounds.

AChE is subjected to substrate inhibition at high ACTI concentration (Stojan, Brochier, Alies, Colletier, \& Fournier, 2004). This can be explained by the enzyme structure as a complex ellipsoid shape protein with a gouge $20 \AA$ deep and $5 \AA$ wide buried deep into the protein shape that contains the substrate recognition and catalytic sites (Silman \& Sussman, 2008; Dvir et al., 2010). The hydrolyzed acetylcholine needs to exit the gouge through the narrow opening before another ACTI molecule can enter, a process that is hindered at high ACTI concentration. Thus, in our assay of activity we have chosen a relatively low substrate concentration of $250 \mu \mathrm{M}$ to minimized substrate inhibition yet high enough to detect low level activity. At this substrate concentration the enzyme velocity was linear with respect to incubation time and enzyme concentration, and increase in activity was also linear with respect to substrate concentration up to the $250 \mu \mathrm{M}$ used (data not shown).

Solubility and stability of flavonoids in aqueous assay mixture are the other important parameters that affect determination of inhibition. The phenols and polyphenols were soluble (up to $100 \mu \mathrm{M}$ ) and stable (60 min at 37 ${ }^{\circ} \mathrm{C}$ ) in the assay mixture containing $10 \%$ methanol (v:v) as judged by absorbance measurement at the $\lambda_{\max }$ of the individual compound (data not shown).

\subsection{Inhibitory Effect of Phenolic and Polyphenolic Compounds}

A number of phenolic and polyphenolic compounds were screened for inhibitory activity against electric eel's AChE activity at an inhibitor concentration of $100 \mu \mathrm{M}$. None of the hydroxybenzoates (4-hydroxybenzoic acid, 3,4-dihydroxybenzoic acid and 3,4,5-trihydroxybenzoic acid) and hydroxylcinnamates (trans-4-hydroxycinnamic acid and trans-3,4-dihydroxycinnamic acid) tested inhibited AChE activity (Table 1). By contrast most of the flavonoids inhibited AChE activity but with a wide range of effectiveness (Table 1). The results indicated that inhibition of $\mathrm{AChE}$ by phenols requires the phenylchroman backbone as a minimum structural requirement, and that the strength of inhibition is related to specific structure. Nonetheless, both curcumin and resveratrol which lack the phenylchroman backbone but are extended polyphenols inhibited ACHE activity but was rather weak with $76.6 \%$ and $55.0 \%$ inhibition at $100 \mu \mathrm{M}$, respectively. 
Table 1. Inhibition of electric eels acetylcholine esterase activity

\begin{tabular}{|c|c|c|}
\hline Compounds & $\%$ Inhibition at $100 \mu \mathrm{M}^{*}$ & $\mathrm{IC}_{50}(\mu \mathrm{M})^{* *}$ \\
\hline \multicolumn{3}{|l|}{ Flavones } \\
\hline Chrysin & $93.3 \pm 4.7^{\mathrm{B}}$ & $18.2 \pm 2.1^{\mathrm{E}}$ \\
\hline Apigenin & $91.5 \pm 3.1^{\mathrm{B}}$ & $7.72 \pm 0.15^{\mathrm{C}}$ \\
\hline Baicalein & $99.6 \pm 0.34^{\mathrm{A}}$ & $0.61 \pm 0.12^{\mathrm{A}}$ \\
\hline Baicalin & $35.8 \pm 6.6^{\mathrm{E}, \mathrm{F}}$ & - \\
\hline Oroxylin A & $31.3 \pm 1.8^{\mathrm{F}}$ & - \\
\hline \multicolumn{3}{|l|}{ Isoflavones } \\
\hline Genistein & $59.03 \pm 0.11^{\mathrm{D}}$ & - \\
\hline Daidzein & $2.64 \pm 0.28^{\mathrm{I}}$ & - \\
\hline \multicolumn{3}{|l|}{ Flavonols } \\
\hline Baohouside I & $38.1 \pm 3.9^{\mathrm{E}}$ & $89 \pm 15^{\mathrm{G}}$ \\
\hline Icarin & ND & - \\
\hline Galangan & $98.0 \pm 2.5^{\mathrm{A}}$ & $19.1 \pm 1.3^{\mathrm{E}}$ \\
\hline Kaempferol & $97.97 \pm 1.3^{\mathrm{A}}$ & $3.05 \pm 0.77^{\mathrm{B}}$ \\
\hline Quercetin & $98.38 \pm 0.39^{\mathrm{A}}$ & $3.60 \pm 0.61^{\mathrm{B}}$ \\
\hline Myricetin & $99.4 \pm 0.37^{\mathrm{A}}$ & $3.95 \pm 0.61^{\mathrm{B}}$ \\
\hline Fisetin & $71.2 \pm 3.6^{\mathrm{C}}$ & - \\
\hline Isoquercitrin (quercetin 3-O- $\beta$-D-glucoside) & ND & - \\
\hline Rutin (quercetin 3-O- $\beta$-D-rutinoside) & ND & - \\
\hline \multicolumn{3}{|l|}{ Flavanones } \\
\hline Pinocembrin & $17.2 \pm 1.7^{\mathrm{H}}$ & - \\
\hline Naringenin & $24.8 \pm 7.3^{\mathrm{G}}$ & - \\
\hline \multicolumn{3}{|l|}{ Flavanols } \\
\hline (-)-Epigallocatechin & $41.35 \pm 0.59^{\mathrm{E}}$ & - \\
\hline (-)-Epigallocatechin gallate & $96.05 \pm 0.16^{\mathrm{A}}$ & $16.83 \pm 0.12^{\mathrm{E}}$ \\
\hline \multicolumn{3}{|l|}{ Anthocyanidins } \\
\hline Pelargonidin & $92.78 \pm 0.21^{\mathrm{B}}$ & $14.27 \pm 0.68^{\mathrm{D}}$ \\
\hline Cyanidin & $92.5 \pm 1.0^{\mathrm{B}}$ & $14.43 \pm 0.31^{\mathrm{D}}$ \\
\hline Delphinidin & $93.73 \pm 0.50^{\mathrm{B}}$ & $44.67 \pm 0.49^{\mathrm{F}}$ \\
\hline Melvidin & $90.60 \pm 0.82^{\mathrm{B}}$ & $41.1 \pm 1.1^{\mathrm{F}}$ \\
\hline \multicolumn{3}{|l|}{ Curcuminoids } \\
\hline Curcumin & $76.6 \pm 2.4^{\mathrm{C}}$ & - \\
\hline \multicolumn{3}{|l|}{ Stilbenes } \\
\hline Resveratrol & $55.0 \pm 1.2^{\mathrm{D}}$ & - \\
\hline \multicolumn{3}{|l|}{ Hydroxybenzoates } \\
\hline 4-Hydroxybenzoic acid & ND & - \\
\hline 3,4-Hydroxybenzoic acid (protocatechuic acid) & ND & - \\
\hline 3,4,5-Hydroxybenzoic acid (gallic acid) & ND & - \\
\hline \multicolumn{3}{|l|}{ Hydroxycinnamates } \\
\hline trans-4-hydroxycinnamic acid (p-coumaric acid) & ND & - \\
\hline trans-3,4-dihydroxycinnamic acid (ferulic acid) & ND & - \\
\hline \multicolumn{3}{|l|}{ Control } \\
\hline Tacrine & - & $0.0254 \pm 0.0032^{1}$ \\
\hline
\end{tabular}

Note. *: Inhibitory effect of compounds was measured at $100 \mu \mathrm{M}$. Percentage inhibition was relative to control reaction without added inhibitor; **: Concentration of compound that produces $50 \%$ inhibition of activity derived from Mean-\%- Inhibition verses $\log \mu \mathrm{M}$ plot $(\mathrm{n}=3)$; ND: None detected; -: Not determined; ${ }^{\mathrm{A}, \mathrm{B}, \mathrm{C}}$ : Values in the same column followed by different superscript were significantly different $(P<0.05)$ in ANOVA and LSD test. 
Some representative flavonoids structures are presented in Figure 1. The flavones apigenin, biacalein and chrysin, the flavonols galangan, kaempferol, quercetin and myricetin, the flavonol (-)-epigallocatechin gallate, and the anthocyanidins perlargonidin, cyanidin, dephinidin and melvidin inhibited more than $90 \%$ of the AChE activity at $100 \mu \mathrm{M}$. The flavones baicalin and oroxylin A, the isoflavones genistein and daidzein, the flavonols baohouside I and fesitin, the flavanones pinocembrin and naringenin, and the flavanol (-)-epigallocatechin were weak inhibitors ranging from 2.64-71.2\% inhibition of activity at $100 \mu \mathrm{M}$. By contrast, isoquercitrin (quercetin 3 -O- $\beta$-D-glucoside), rutin (quercetin 3-O- $\beta$-D-rutinoside) and icarin were inactive.

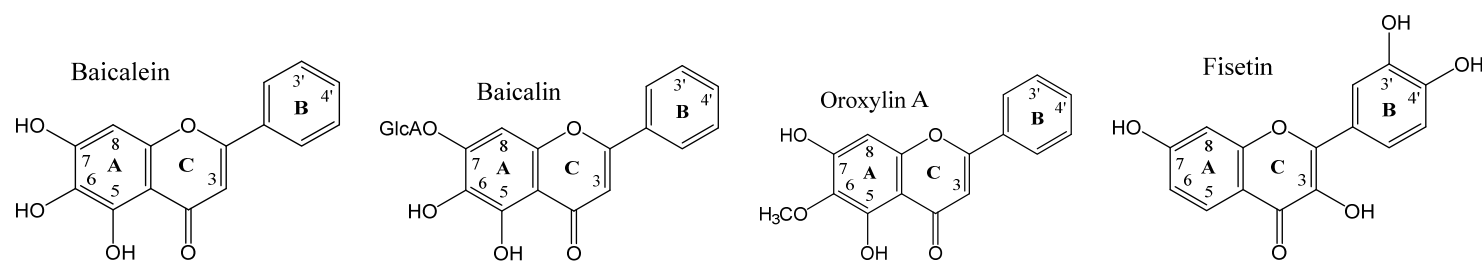<smiles></smiles>

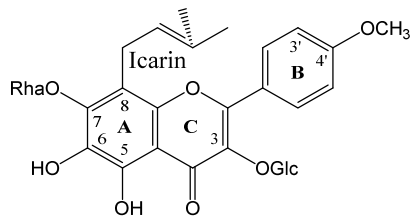

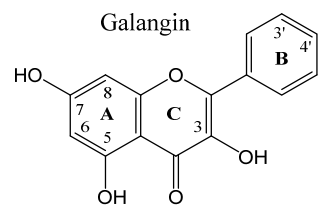

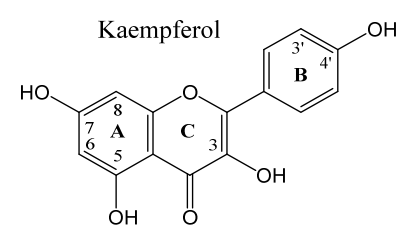<smiles>CC12CCC(O1)C1C(=O)C=C(c3ccccc3)OC12C</smiles><smiles>CC12CCC(Oc3c(O)cc(O)cc31)C(=O)CC2c1ccccc1</smiles>

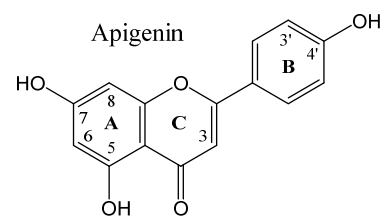

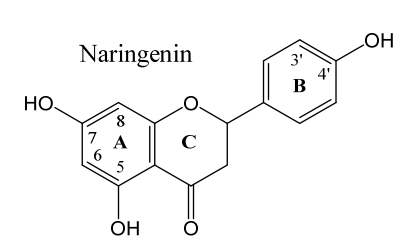<smiles></smiles><smiles></smiles><smiles></smiles>

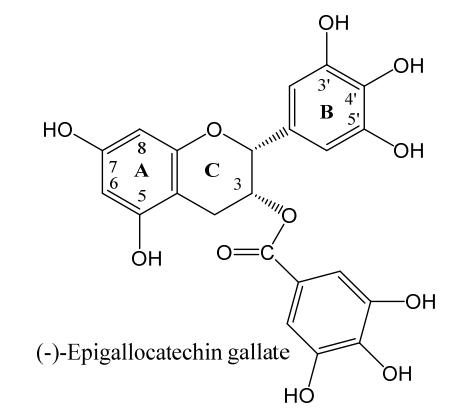

Figure 1. Structures of baicalein and other representative flavonoids used in the study

\subsection{IC50 Values of Flavonoids}

In order to derive a more quantitative evaluation of the inhibitory potency of the strongly inhibiting flavonoids and to derive some structure-activity relationships, the concentration of each flavonoid required for inhibiting AChE activity by $50 \%$ (IC50) was determined (Table 1). This was obtained by measuring activity in the presence of a range of inhibitor concentrations and from the non-linear inhibition response a plot of \% inhibition (of activity) verses $\log$ concentration (of inhibitor) was produced as illustrated for baicalein (Figure 2). The results 
showed that baicalein, a major flavone derived from the roots of Scutellaria baicalensis, was the most potent inhibitor with a rather low IC50 of $0.61 \mu \mathrm{M}$. Nonetheless, this value was 25.5 fold higher (therefore weaker) than the powerful and therapeutically prescribed AChE inhibitor tacrine, which was used as a positive control in our assay with an IC50 of $25.4 \mathrm{nM}$.

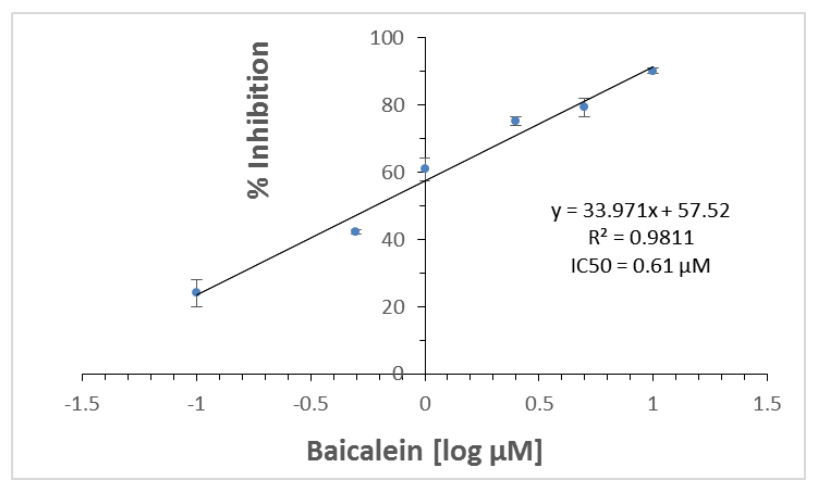

Figure 2. Inhibition of electric eel's acetylcholine esterase activity by baicalein

Inhibition by kaempferol, quercetin and myricetin were also strong which displayed similar $(P<0.05)$ IC50 values that ranged from 3.05-3.95 $\mu \mathrm{M}$ (Table 1). Inhibition by the other flavonoids were less strong, with order of effectiveness beginning with apigenin $(7.72 \mu \mathrm{M})$, perlargonidin $(14.27 \mu \mathrm{M})$, cyanidin $(14.43 \mu \mathrm{M})$, (-)-epigallocatechin gallate $(16.83 \mu \mathrm{M})$, chrysin $(18.2 \mu \mathrm{M})$, galangan $(19.1 \mu \mathrm{M})$, melvidin $(41.1 \mu \mathrm{M})$, dephinidin $(44.67 \mu \mathrm{M})$ and, lastly, baohouside I $(89 \mu \mathrm{M})$.

Our result contrasted with that of Guo et al. (2010) which reported baicalein a weak inhibitor and galangan a stronger inhibitor of $\mathrm{AChE}$ when tested on rat adult brain tissue homogenate. Beside differences in the source (rat brain verses electric eels) and state (homogenates verses purified enzyme) of AChE used, that study employed a much higher concentration of acetylthiocholine substrate $(0.5 \mathrm{M})$ and inhibition was determined at one fixed concentration of inhibitor $(20 \mu \mathrm{M})$.

Katalinic et al. (2010) proposed that phenolic compounds are able to interact with amino acid residues defining the active site gorge of AChE via hydrogen bond, hydrophobic and $\pi-\pi$ interaction. Multiple hydroxyl groups in the phenolic compound structure were believed to enhance the inhibitory activity because of stronger binding capacity (Fale, Asvensao, Serralheiro, \& Haris, 2012). These proposals explain the inhibitory properties of most but not all phenolic compounds. Our results showed the minimum requirement of the flavonoid backbone as a minimum structural requirement. In addition, the position, number and substitution of hydroxyl groups and the oxidation state of the $\mathrm{C}$-ring of the flavonoid structure determine their effectiveness in inhibiting AChE activity.

\subsection{Evaluation of Structure-Activity Relationships Based on IC50 Values}

The IC50 values of the flavonoids presented in Table 1 allowed us to evaluate some structure-activity relationships. The strong inhibition shown by baicalin suggested that the flavone A-ring A5-OH, A6-OH and A7-OH groups play a major role in inhibiting AChE activity. Indeed, losing of any of these A-ring hydroxyl groups as in baicalin (glucuronidated A7-OH), oroxylin A (methylated A6-OH) and fisetin (minus A5-OH and A6-OH) greatly diminished inhibitory activity as indicated by their weak inhibitions at $100 \mu \mathrm{M}$. The inhibitory activity of galangan (IC50 19.1 $\mu \mathrm{M}$ ) which lack A6-OH was significantly weaker than baicalein (IC50 $0.61 \mu \mathrm{M}$ ). All these inhibition features point to the combine requirements of the $\mathrm{A} 5-\mathrm{OH}, \mathrm{A} 6-\mathrm{OH}$ and $\mathrm{A} 7-\mathrm{OH}$ groups in providing strong inhibition of AChE activity.

The importance of the A7-OH group for inhibition was further shown by comparing icarin which contained a A8-prenyl group but lack a free A7-OH (rhamnosylated) and has no measurable activity at $100 \mu \mathrm{M}$, to baohuoside I which also contained a A8-prenyl group but retain free A7-OH and was fairly active (IC50 $89 \mu \mathrm{M}$ ). The effect of the A8-prenyl group negatively impacted on the strength of inhibition as baohuoside I was a much weaker inhibitor than baicalein which is not modified at A8.

The IC50 determinations also indicated the participation of the flavonoids B-ring B4'-OH in AChE inhibition. For the flavonol series, galangan $(19.1 \mu \mathrm{M})$ with has no C4'-OH was 6-fold weaker than kaempferol $(3.05 \mu \mathrm{M})$, quercetin $(3.60 \mu \mathrm{M})$ and myricetin $(\mathrm{I} 3.95 \mu \mathrm{M})$ in inhibiting AChE. The fact that there were no significant 
differences $(P<0.05)$ in IC50 between kaempferol, quercetin and myricetin indicated that only the B4'-OH, but not the B3'-OH and B5'-OH, contributes toward stronger inhibition. Nonetheless, the flavonols were weaker inhibitors than baicalein which does not process B-ring hydroxyl groups but has the additional A6-OH group.

Another structural feature contributing towards strong inhibitory activity is the C-ring double bond between $\mathrm{C} 3$ and $\mathrm{C} 4$. The unsaturation of the C-ring is known to increase planarity of the chroman moiety in the flavonoid structure that enhanced, amongst other things, antioxidant activity. Thus, chrysin (IC50 18.2 $\mu \mathrm{M}$ ) was a stronger inhibitor than pinocembrin, and apigenin (IC50 $7.72 \mu \mathrm{M}$ ) a stronger inhibitor than naringenin.

The C-ring $\mathrm{C} 3-\mathrm{OH}$ does not appear to contribute to inhibitory activity as galangan, which lack the $\mathrm{C} 3-\mathrm{OH}$ group, was as effective as chrysin in inhibiting AChE. However, iappears that stearic hindrance due to the presence of a sugar moiety at the $\mathrm{C} 3-\mathrm{OH}$ site totally abolished inhibitory activity as shown by the lack of inhibition observed with isoquercitrin and rutin.

Our screening of flavonoids also identified the anthocyanidins pelargonidin $(14.27 \mu \mathrm{M})$, cyanidin $(14.43 \mu \mathrm{M})$, delphinidin $(44.67 \mu \mathrm{M})$ and malvidin $(41.1 \mu \mathrm{M})$ as relatively strong inhibitors of AChE with IC50 in the low $\mu \mathrm{M}$ level. Anthocyanidins in similarity to the flavonols processes $\mathrm{A} 5-\mathrm{OH}$ and $\mathrm{A} 7-\mathrm{OH}$ groups required for inhibition. At the near neutral $\mathrm{pH}$ of the assay these anthocyanidins exist as the positively charge flavylium cation thus would negatively impact on their intestinal absorption affecting their bioavailability for in vitro function.

Increased gallation of catechin also increased inhibitory activity as shown by the much stronger inhibition with (-)-epigallocatechin gallate compared to (-)-epigallocatechin, even though it is the $\mathrm{C} 3-\mathrm{OH}$ that was gallated. Unlike the flavonols, the C-ring in catechin does not process $\mathrm{C} 2-\mathrm{C} 3$ double bonds and thus are more flexible structurally.

\subsection{Enzyme Kinetic Mode of Inhibition of Baicalein against Electric Eel AChE}

Inhibitory kinetic assay was conducted to identify baicalein mode of inhibition and the data analysed by graphical means using Lineweaver-Burk plot. The results showed that all the data lines intersected in the second quadrant of the plot indicating a mixed-type of inhibition (Figure 3A). Mixed inhibition is an intermediate of competitive and uncompetitive inhibition (Burlingham \& Widlanski, 2003). As a mixed inhibitor, baicalein was able to bind either the free acetylcholinesterase or the acetylcholinesterase-substrate (ACTI) complex.

There are two types of inhibition constants in mixed inhibition, which are $K_{1}$ and $K_{2}$ and which denote the equilibrium constant of dissociation of the inhibitor bound enzyme complex and the inhibitor-bound enzyme substrate complex, respectively. The values of $\mathrm{K}_{1}$ and $\mathrm{K}_{2}$ for baicalein were determined from the secondary plots of the slope and Y-intercept (from the Lineweaver-Burk plot) versus inhibitor concentration (Figures 3B and 3C) and they were 0.91 and $1.98 \mu \mathrm{M}$, respectively. These inhibition constants indicate the relative inhibitory potency baicalein to the free enzyme $\left(\mathrm{K}_{1}\right)$ and the enzyme-substrate complex $\left(\mathrm{K}_{2}\right)$.

The kinetic inhibition results also showed that the baicalein's $\mathrm{K}_{1}$ was lower than its $\mathrm{K}_{2}$, indicating that baicalein tended to bind more easily and firmly to the free acetylcholinesterase than to the acetylcholinesterase-ACTI complex. In mixed inhibition, at sufficiently high substrate concentrations the enzyme is exclusively present in the form of enzyme-substrate complex and inhibitor acts primarily as an uncompetitive inhibitor which attempts to bind to the complex. Under this condition, a higher concentration of the inhibitor is required to effectively inhibit the enzyme. Consequently, the concentration of the compound necessary for decreasing of $50 \%$ of the enzyme activity (IC50 baicalein $0.61 \mu \mathrm{M}$ ) tends to approximate the $\mathrm{K}_{2}$ value. However, this was not observed for baicalein under the assay conditions in which the concentration of ACTI substrate was at $250 \mu \mathrm{M}$. 


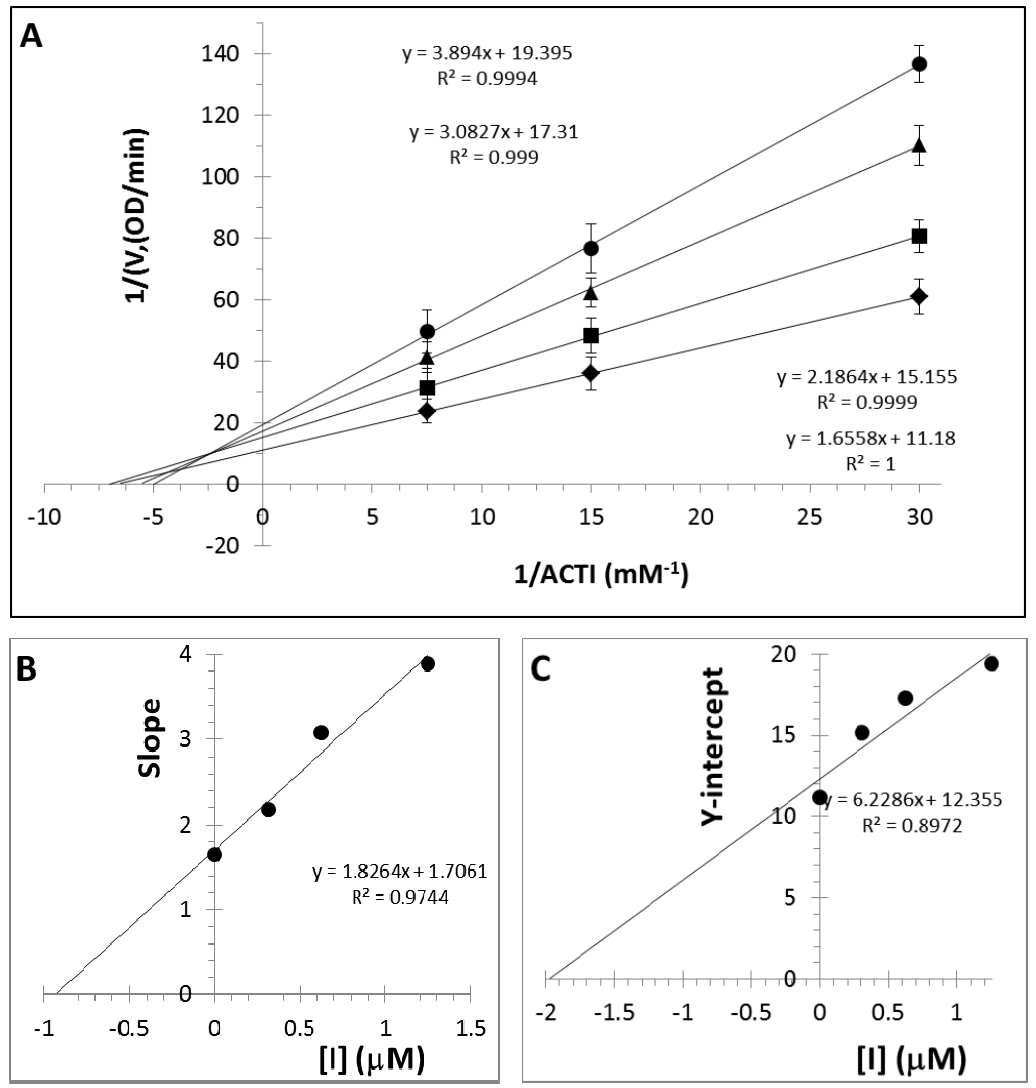

Figure 3. Graphical determination of the mode of inhibition of baicalein. (A) Lineweaver-Burk plots $(1 / \mathrm{V}$ versus $1 /[\mathrm{ACTI}])$ for the inhibition of baicalein $(0[\bullet], 0.625[\mathbf{\bullet}], 1.25[\mathbf{\bullet}]$, and $2.5[\bullet] \mu \mathrm{mol} / \mathrm{L})$ on the catalytic activity of electric eels acetylcholinesterase with $3.75,75$ or $15 \mathrm{mM} \mathrm{ACTI}$ substrate. Error bar shows SD of mean $(\mathrm{n}=4)$. Reaction conditions were as follows: $2.7 \mathrm{mU} / \mathrm{mL}$ of AChE in $0.11 \mathrm{~mol} / \mathrm{L}$ potassium phosphate buffer ( $\mathrm{pH} 7.4$ ) and $10 \%$ (v:v) methanol with the addition of varying concentrations of baicalein and ACTI, and incubated at 37

${ }^{\circ} \mathrm{C}$ for $60 \mathrm{~min}$. (B) Secondary plot of slope versus inhibitor concentration used to determine the inhibition constant $\mathrm{K}_{1}$. (C) Secondary plot of Y-intercept versus inhibitor concentration used to determine inhibition constant $\mathrm{K}_{2}$

\section{Conclusion}

The AChE inhibitory activity of flavonoids is related to the number and position of hydroxyl groups and the unsaturation of the C-ring. The A-ring A5-OH, A6-OH and A7-OH groups are the most important determinant of inhibitory activity. Baicalein is the most potent flavonoid inhibitor of electric eels AChE with an IC50 of 0.61 $\mu \mathrm{M}$. Enzyme kinetic analysis indicated that baicalein is a mixed type inhibitor with $\mathrm{K}_{1}$ and $\mathrm{K}_{2}$ of 0.91 and 1.96 $\mu \mathrm{M}$, respectively. However, the efficacy of baicalein or any other flavonoids as preventative oral AChE inhibitor agent or use in the management of dementia would depends on its bioaccessibility and bioavailability. The later especially so as the target organ in Alzheimer's disease is the brain where the drug molecule is required to cross the blood-brain barrier.

\section{References}

Adams, M., Gmunder, F., \& Hamburger, M. (2007). Plants traditionally used in age related brain disorders: A survey of ethnobotanical literature. Journal of Ethnopharmacology, 113(3), 363-381. http://dx.doi.org/10.1016/j.jep.2007.07.016

Anand, P., \& Singh, B. (2013). A Review on cholinesterase inhibitors for Alzheimer's disease. Archives of Pharmacol Research, 36, 375-399. http://dx.doi.org/10.1016/j.bmc.2011.05.027

Burlingham, B. T., \& Widlanski, T. S. (2003). An intuitive look at the relationship of Ki and IC: A more general use for the Dixon plot. Journal of Chemical Education, 80(2), 214-218. http://dx.doi.org/10.1021/ed080p214 
Dvir, H., Silman, I., Harel, M., Rosenberry, T. L., \& Sussman, J. L. (2010). Acetylcholinesterase: From 3D $\begin{array}{lllll}\text { structure to function., } & \text { Chemico-Biological Interactions, } & 187, & 10-22 .\end{array}$ http://dx.doi.org/10.1016/j.cbi.2010.01.042

Ellman, G. L., Courtney, K. D., Andres, V., \& Featherstone, R. M. (1961). A new and rapid colorimetric determination of acetylcholinesterase activity. Biochemistry and Pharmacology, 7, 88-95. http://dx.doi.org/10.1016/0006-2952(61)90145-9

Ellison, S. L. R., \& Williams, A. (2012). Eurachem/CITAC guide: Quantifying uncertainty in analytical measurement (3rd ed.). Retrieved from http://www.eurachem.org

Fale, P. L. V., Ascensao, L., Serralheiro, M. L., \& Haris, P. I. (2012). Interaction between Plectranthus basbatus herbal tea components and acetylcholinesterase: Binding and activity studies. Food \& Function, 3, 1176-1182. http://dx.doi.org/10.1039/C2FO30032J

Geula, C., \& Darvesh, S. (2004). Butyrylcholinesterase, cholinergic neurotransmission and the pathology of Alzheimer's disease. Drugs Today, 40(8), 711-721. http://dx.doi.org/10.1358/dot.2004.40.8.850473

Guo, A. J. Y., Xie, H. Q., Choi, R. C. Y., Zheng, K. Y. Z., Bi, C. W. C., Xu, S. L., ... Tsim, K. W. K. (2010). Galangin, a flavonol derived from Rhizoma Alpiniae Officinarum, inhibits acetylcholinesterase activity in vitro. Chemico-Biological Interactions, 187, 246-248. http://dx.doi.org/10.1016/j.cbi.2010.05.002

Hardy, J., \& Selkoe, D. J. (2002). The amyloid hypothesis of Alzheimer's disease: Progress and problems on the road to therapeutics. Science, 353, 353-357. http://dx.doi.org/10.1126/science.1072994

Holtzman, D. M, John, C. M., \& Goate, A. (2011). Alzheimer's disease: The Challenge of the second century. Science Translation Medicine, 3(77), 77-81. http://dx.doi.org/10.1126/scitranslmed.3002369

Katalinic, M., Rusak, G., Barovic, J. D., Sinko, G., Jelic, D., Antolovic, B., \& Kovarik, Z. (2010). Structural aspects of flavonoids as inhibitors of human butyrylcholinesterase. European Journal of Medicinal Chemistry, 45(1), 186-192. http://dx.doi.org/10.1016/j.ejmech.2009.09.041

Khan, M. T. H., Orhan, I., Senol, F. S., Kartal, M., Sener, B., Dvorska, M., ... Slapetova, T. (2009). Cholinesterase inhibitory activities of some flavonoids derivatives and chosen xanthone and their molecular $\begin{array}{lllll}\text { docking } & \text { studies. } & \text { Chemico-Biological } & \text { Interactions, } & \text { 181(3), }\end{array}$ http://dx.doi.org/10.1016/j.cbi.2009.06.024

Kim, J. Y., Lee, W. S., Kim, Y. S., Curtis-Long, M. J., Lee, B. W., Ryu, Y. B., \& Park, K. H. (2011). Isolation of cholinesterase-inhibiting flavonoids from Morus Ihou. J Agri Food Chem, 59(9), 4589-4596. http://dx.doi.org/10.1021/jf200423g

Li, R. S., Wang, X. B., Hu, X. J., \& Kong, L. Y. (2013). Design, synthesis and evaluation of flavonoid derivatives as potential multifunctional acetylcholinesterase inhibitors against Alzheimer's disease. Bioorganic \& Medicinal Chemistry Letters, 23, 2636-2641. http://dx.doi.org/10.1016/j.bmcl.2013.02.095

Liu, C., Wu, J., Gu, J., Xiong, Z., Wang, F., \& Wang, J. (2007). Baicalein improves cognitive deficits induced by chronic cerebral hypoperfusion in rats. Pharmacology Biochemistry and Behavior, 86, 423-430. http://dx.doi.org/10.1016/j.pbb.2006.11.005

Marek, B., Wieckowska, A., Hebda, M., Guzior, N., Sotriffer, C. A., \& Malawska, B. (2013). Structure-based search for new inhibitors of cholinesterase. International Journal of Molecular Sciences, 14(3), 5608-5632. http://dx.doi.org/10.3390/ijms14035608

Mehta, M., Adem, A., \& Sabbagh, M. (2012). New acetylcholinesterase inhibitors for Alzheimer's disease. International Journal of Alzheimer's disease, 201(2), 1-8. http://dx.doi.org/10.1155/2012/728983

Mesulam, M. M., Guillozet, A., Shaw, P., Levey, A., Duysen, E. G., \& Lockridge, O. (2002). Acetylcholinesterase knockouts establish central cholinergic pathways and can use butyrylcholinesterase to hydrolyze acetylcholine. Neuroscience, 110(4), 627-39. http://dx.doi.org/10.1016/S0306-4522(01)00613-3

Nigel, H. G., Utsuki, T., Ingram, D. K., Wang, Y., Pepeu, G., Scali, C., ... Lahiri, D. K. (2005). Selective butyrylcholinesterase inhibition elevates brain acetylcholine augments learning and lowers Alzheimer's $\beta$-amyloid peptide in rodent. Proceedings of the National Academy of Sciences, 102(47), 17213-17218. http://dx.doi.org/10.1073/pnas.0508575102

Racchi, M., Mazzuccelli, M., Porrello, E., Lanni, C., \& Govoni, S. (2004). Acetylcholinesterase inhibitors: Novel activities of old molecules. Pharmacological Research, 50, 441-451. http://dx.doi.org/10.1016/j.phrs.2003.12.027 
Silman, I., \& Sussman, J. L. (2008). Acetylcholinesterase: How is structure related to function? Chemico-Biological Interactions, 175, 3-10. http://dx.doi.org/10.1016/j.cbi.2008.05.035

Stojan, J., Brochier, L., Alies, C., Colletier, J. P., \& Fournier, D. (2004). Inhibition of Drosophila melanogaster acetylcholinesterase by high concentrations of substrate. Eur. J. Biochem., 271, 1364-1371. http://dx.doi.org/10.1111/j.1432-1033.2004.04048.x

Tayeb, H. O., Yang, H. D., Price, B. B. H., \& Tarazi, F. I. (2012). Pharmacotherapies for Alzheimer's disease: Beyond cholinesterase inhibitors. Pharmacology \& Therapeutics, 134, 8-25. http://dx.doi.org/10.1016/j.pharmthera.2011.12.002

Wang, W., Wang, F., Yang, Y. J., Hu, Z. L., Long, L. H., Fu, H., ... Chen, J. C. (2011). The flavonoid baicalein promotes NMDA receptor-dependent long-term potentiation and enhances memory. British Journal of Pharmacology, 162, 1364-1379. http://dx.doi.org/10.1111/j.1476-5381.2010.01143.x

Wollen, K. A. (2010). Alzheimer's disease: the pros and cons of pharmaceutical, nutritional, botanical, and stimulatory strategies from the perspective of patients and practitioners. Alternative Medicine Review, 15(3), 313-325.

\section{Copyrights}

Copyright for this article is retained by the author(s), with first publication rights granted to the journal.

This is an open-access article distributed under the terms and conditions of the Creative Commons Attribution license (http://creativecommons.org/licenses/by/3.0/). 